\title{
What Multi-Level Solutions Can Simultaneously Promote Zambian Mine Workers' Health and Benefits to Mining Companies?
}

\author{
By Barbara Son ${ }^{*}$ Francis Wambalaba ${ }^{ \pm}$, Mwadi Kakoma Chakulya ${ }^{*}$ \& \\ Mark Simonian $^{+}$
}

\begin{abstract}
Employers have long recognized the importance of promoting employee health, as it contributes to an organization's overall success, both in keeping employees productive and in maintaining a higher level of employee retention. Particularly in high-hazard industries, such as the mining industry, employer-sponsored medical services for employees are essential. Despite this crucial role of employee health in successful business enterprises, there is a lack of in-depth published research considering employee health issues from the employees' perspective. Research into healthcare issues in Africa and the African mining industry, with an emphasis on its employees, helps to fill this gap and to identify key factors in fostering better employee health-particularly the health of mine workers - worldwide. Our study research focuses on the Konkola Copper Mines $(K C M)$ in Zambia, Africa, surveying 285 KCM employees and nine management staff in 2016. The study identified the following factors that make company-sponsored healthcare services important both to KCM and to its employees: employee financial protection, employee health and productivity, employee retention, and employee morale. Our findings affirm that multi-level solutions - including strategies that better engage different participants in healthcare services delivery - will more successfully promote both mine workers' health and also greater mining company profits through a reduction in human resource costs. These multi-level strategies can include employer commitment to increasing the quality of company-sponsored healthcare, removing inefficiencies in healthcare delivery and procurement of services, increasing investment in medical equipment, increasing employee and union buy-in, banking and earmarking employee contributions for their more specific healthcare needs, and attracting commercial healthcare sponsorship and pharmaceutical co-branding.
\end{abstract}

Keywords: occupational health and safety, health promotion, mining industry, Zambia

\section{Introduction}

Employee health is a multi-layered concern, impacted by a myriad of intertwined social, economic, cultural, political, and environmental influences, perspectives, and priorities. In light of ecological models, promotion of employee health is most effective when these interwoven but often competing issues are targeted simultaneously. Yet, "multilevel interventions that better incorporate social, institutional, and policy approaches to health promotion, have gone largely unheeded" (Golden and Earp 2012: 368). In particular, Zambia has been

\footnotetext{
*Professor, Anaheim University, USA.

${ }^{ \pm}$Professor, United States International University, Kenya.

${ }^{\ddagger}$ Medical Superintendent, Konkola Mine Hospital, Zambia.

${ }^{+}$Adjunct Professor, California State University, USA.
} 
experiencing high rates of malaria and non-communicable diseases (NCDs) of the circulatory system recently, with significant consequences on mortality. In fact, it was estimated that NCDs contributed to $29 \%$ of all mortality in Zambia during 2016, while communicable diseases along with maternal, perinatal, and nutritional conditions accounted for $61 \%$ of all mortality during that same period (WHO 2018). Over the past 15 years, some newly formed, struggling mining companies in Zambia have been forced to reduce or even abandon social services and amenities, including company-run healthcare facilities for employees. Other mining healthcare facilities have undergone management buyouts, further reducing the direct commitment of their former mining company sponsors.

Many factors contribute to mining companies' indifference to continued operation of these healthcare facilities, including the lack of interest of foreign investors in running health services; poor copper prices on the international market; and increasing costs, particularly operational costs, in the mining industry (World Factbook 2020, Hairong and Sautman 2013). The Zambian mining industry in particular faces challenges in maintaining an aging infrastructure, most notably in healthcare facilities, where demand for modernized equipment, facilities, and services are on the rise. In addition, retaining highly qualified healthcare professionals has posed a formidable financial challenge (Ministry of Health Zambia and EQUINET 2018, Nkombo and Abubakar 2002).

In high-hazard industries such as the mining industry, employer-sponsored medical services are essential to employees, who may have few other feasible alternatives for much-needed general and industry-specific treatments, therapies, medications, rehabilitation, and preventatives. Employer investment in employee healthcare is shown to garner employee satisfaction and employee commitment/ goodwill toward the employer, generally regarded as positives for attracting new employees in often-difficult labor markets (Hendriksen et al. 2016). Nevertheless, beyond these types of studies and conclusions from the employers' perspective, there is a decided lack of published, in-depth research considering employee healthcare issues from the employees' perspective, specifically in the Zambian mining industry. Our 2016 research and survey conclusions fill this gap, investigating various factors that make employee healthcare services important to employees and prospective employees, leading also to benefits for mining company employers. Our research also provides KCM's medical management team and teams in similar organizations with factors to consider when they evaluate which strategies most effectively promote workers' health, so that they can more effectively implement improvements.

\section{Literature Review}

\section{Mining Safety and Health}

The Zambian mining sector can improve mine workers' health and safety most effectively by treating operational risk management as a full-fledged function within their organizations, while benchmarking advanced operational control 
methods (Muchemwa and Karim 2017). This coordinated approach requires a commitment from senior management that safety management programs will be administered effectively and efficiently. To mitigate hazards and the concomitant risks, mining company management should increase employee participation in risk management activities and improve safety training practices (Muchemwa and Karim 2017). Although a wide variety of intervention measures can improve workers' health and safety, a specific targeted intervention method seems to be more effective in reducing coal mining accidents (Tong et al. 2019).

Drawing on an array of historical evidence, Walters and Quinlan (2019) point out that a resistance-model of mobilization can help explain coal miners' motivations for seeking voices on occupational health and safety (OHS) matters. Yet, as an OHS system is bureaucratized, mineworkers lose voices on safety issues. Hence, Stewart et al. (2019) propose a broader conceptualization of OHS, which enables the understanding of its environment in new, wide-ranging practical and political dimensions. In addition to an improved conceptualization of OHS, to protect workers and minimize worker injuries and deaths, mining companies must comprehend how best to comply with high OHS standards, and what methodologies actually work best in practice. A multi-faceted, multi-level health and safety climate survey tool can improve the understanding of OHS outcomes (Parker et al. 2017, Nyström et al. 2018).

To address a greatly elevated mortality rate for former miners in South Africa, Bloch et al. (2018) called for coordinated, cooperative action involving not only the for-profit mining sector, but also governments and nonprofit organizations. Osewe (2015) proposed various forms of issue-focused partnerships to promote the mining sector's adherence to higher health and safety standards. By successfully leveraging these partnerships, researchers argue that the mining industry ultimately would gain, by employing and retaining healthier, more productive workers.

\section{Employee Healthcare}

The net gain for industrial employers from improved employee healthcare has been well documented. For example, a recent study of a South African mining company with a high prevalence of HIV in its workforce revealed that the benefits from antiretroviral therapy programs far outweighed the costs. Those benefits included reducing employees' need to use company-sponsored healthcare and also avoiding productivity losses due to worker illness, absenteeism, and turnover (Meyer-Rath et al. 2015). Another benefit for industrial employers from providing health services for employees is that management ensures employees have ready access to more reliable healthcare, to earlier diagnosis, and to timely treatment. This ready access makes it possible for employees to return to work earlier, due to speedier recoveries, again avoiding productivity losses (Ammendolia et al. 2016, Reddick and Coggburn 2007). Michaels and Greene (2013) also confirm that worksite wellness programs promote employee health, helping to reduce an organization's direct and indirect healthcare costs. For example, in another case study of the horticulture industry in Kenya, Kaol and Wambalaba (2011) found 
that besides running its own clinic, Homegrown subsidized meals and health services at a total cost of about Kshs 137 million.

Businesses have realized that by failing to invest in employee healthcare leads to substantially higher indirect costs, such as employee absenteeism, lost productivity from added sick days, and even the loss of qualified labor (Troy 2016). Affirming this cost-benefit analysis, a recent study by US companies disclosed that poor employee health cost a whopping 200 to $300 \%$ more in the indirect costs than the companies expended in the direct costs of providing better employee health benefits (Porter et al. 2008). Therefore, the overwhelming empirical evidence demonstrates that, despite the significant upfront, ongoing expenditures to provide improved employee healthcare, employers should prefer to maintain employee healthcare plans and even increase benefits, rather than curtailing them or terminating them altogether and incurring substantially greater costs.

Additionally, by directly providing healthcare or managing self-funded plans rather than utilizing third-party healthcare vendors, an organization can dramatically reduce its healthcare costs. The savings stem from fewer administrative costs and better control over healthcare expenditures, avoiding higher outsourcing fees. Moreover, by being closer to the employees and their jobs, an organization can have a far better understanding of employee health patterns, which, in turn, enables the organization to implement appropriate, specific, and more effective preventive and rehabilitative programs. In addition, by having readily available healthcare information, an organization is empowered with a better understanding of actual employee healthcare costs; an organization may better control cash flows, as healthcare payments are made on betterdiagnosed, verifiable employee illnesses and injuries (Eyestone et al. 2014, SelfInsurance Institute of America 2009). As an even further benefit, employer-based health coverage protects employees from the financial exposure associated with high medical treatment costs or catastrophic health conditions (Blumberg et al. 2012).

\section{Health Interventions}

Improving the quality of health care and service delivery adds value to organizations, as it facilitates better health outcomes for organizational investments (Parker et al. 2017, HRET 2015). According to the systematic view of work organizations, employee health is closely tied to organizational effectiveness. Building a healthy organizational culture is critical to promoting organizational effectiveness and employee health (Di Fabio 2017, Grawitch and Ballard 2016, Sadia 2016). However, creating a culture of health takes passionate, persistent, and persuasive leadership. Effective leadership, healthy behavior, and spirituality achieve more positive results for employees and, ultimately, for their organizations (Son and South-Winter 2018, Dixon-Fyle et al. 2012).

The moral hazard theory argues that when people bear a higher health cost burden, they more deliberately and drastically seek healthcare cost savings (Gould 2013). This quest for savings often is counterproductive and more costly because 
an employee's failure to obtain healthcare can lead to greater negatives for the employee and for the organization, including a lengthier and more expensive treatment period, more lost time from work, and possibly disability or even death. Thus, multi-pronged organizational interventions should be aimed at promoting a culture of employee health and safety in multi-dimensional healthcare settings (Gray et al. 2019, Tong et al. 2019). Interventions that adequately embed multilevel worksite wellness programs can improve employee health and work performance (Hendriksen et al. 2016, Bakker and Demerouti 2018).

Another significant advantage of employer-based healthcare services is that they reflect positively on the organization's image and social responsibility, not only by addressing employee healthcare needs but also by demonstrating a tangible commitment to the employees' communities. Healthcare services can be a medium for building community trust and better stakeholder engagement, by demonstrating that organizations are developmental and social partners interested in enhancing the welfare of the communities that surround their operations (Murphy 2015). For this reason, mining companies should forge a long-term partnership with their communities and local health authorities, to reduce the burden of disease and illness on those organizations (Osewe 2015). In addition, mining companies should realize that, by investing in public health in surrounding communities, they garner long-term benefits, such as sourcing healthy employees (Troy 2016, Ministry of Health Zambia and EQUINET 2018).

\section{Methodology}

We used the descriptive study design to address employer-based health services for mining workers (Prowle and Harradine 2015, HRET 2015). The survey was conducted among KCM employees who were based in the towns of Chingola, Kitwe, and Chililabombwe in Zambia over a two-month period (i.e., from June to July 2016). The KCM company had a workforce population of approximately 7,000 employees in 2016. The study targeted employees at all levels, including senior KCM management (KCM grade 5 to 8 ) and general KCM employees (KCM grade 1 to 4 ).

Clustered stratified random sampling techniques were used to obtain a representative sample of the KCM employees, as illustrated in Figure 1. The clustering units were based on the integrated business units (IBUs) or geographical location of where the employees work from. Employees in the respective IBUs were further stratified based on their $\mathrm{KCM}$ grade by the proportion (\%) of that grade in the entire KCM population and for that IBU. A sample size of 300 employees and 10 management staff in KCM was used for study, based on calculations done from a sampling size table: $95 \%$ confidence level and a 5\% margin of error and a population size of 7,000 . 
Figure 1. Sampling Technique

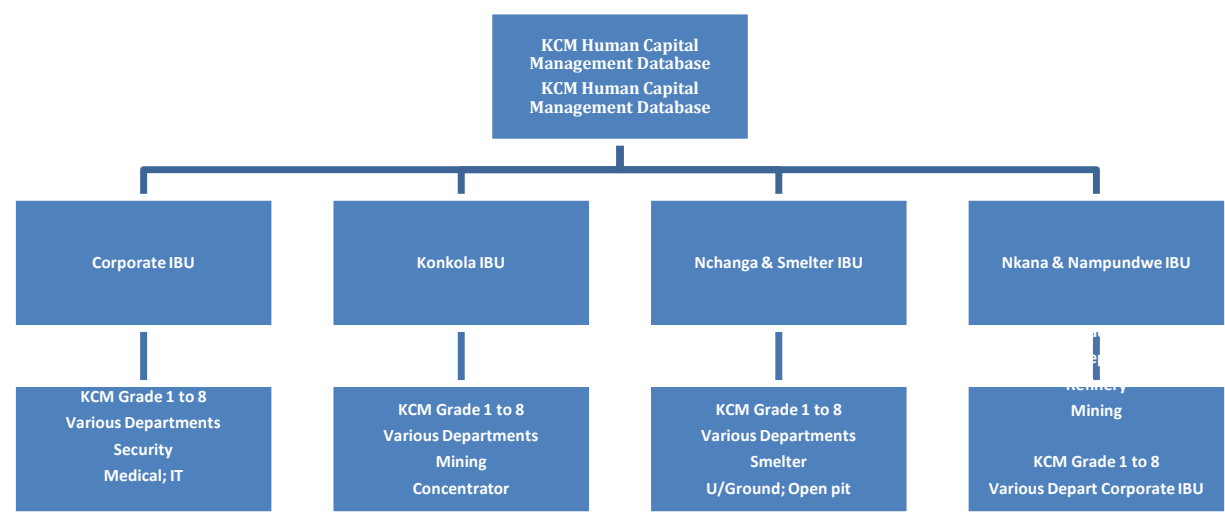

Out of a sample size of 300, 285 employees were able to participate in the survey. By gender, participating KCM employees in the five IBUs were 208 males $(73 \%)$ and 77 females (27\%). Most of the KCM survey respondents were from Nchanga IBU which is the largest KCM IBU. The mean age of survey respondents was 40 years old, and most of the survey respondents were between the ages of 31 and 35 years old $(20.4 \%)$. Survey respondents who were 25 years old or younger had worked for the company for five years or less, whereas the majority of survey respondents over 55 years old had worked for the company for six to 10 years.

For the reliability of survey data, we employed two pretested structured questionnaires, which were self-administered among employees in the various IBUs. Research assistances aided employees requiring translation of the survey questions. Senior KCM management involved in the supervision of medical services also completed self-administered questionnaires. These questionnaires were pilot-tested, to improve both the wording of the survey questions and the overall flow of the survey. Weaknesses were addressed and modifications made, to improve the survey questionnaire before final administration. Data was entered and analyzed for descriptive statistics, using IBM SPSS statistics and Stata statistical software.

\section{Results}

Over $62 \%$ of the employees who participated in the survey were union workers (KCM 1 to 4 ). Most of these employees were 45 years of age or younger and had worked for six to 10 years for the organization. 
Table 1. Factors Attributed to the Importance of Medical Services among Employees

\begin{tabular}{|c|c|c|c|c|c|}
\hline Factor & & & Rating (\% & & \\
\hline & $\begin{array}{c}\text { Strongly } \\
\text { Agree }\end{array}$ & Agree & $\begin{array}{l}\text { Neither } \\
\text { Agree nor } \\
\text { Disagree }\end{array}$ & Disagree & $\begin{array}{l}\text { Strongly } \\
\text { Disagree }\end{array}$ \\
\hline Provides financial protection & 41.5 & 44.4 & 5.93 & 5.6 & 2.6 \\
\hline $\begin{array}{l}\text { Contributes to family members } \\
\text { staying healthy }\end{array}$ & 37.8 & 50.6 & 5.8 & 2.6 & 3.7 \\
\hline $\begin{array}{l}\text { Contributes to employees } \\
\text { staying healthy }\end{array}$ & 41.7 & 48.9 & 4.7 & 2.5 & 2.2 \\
\hline $\begin{array}{l}\text { Helps employees remain } \\
\text { productive }\end{array}$ & 41.3 & 47.1 & 7.3 & 2.9 & 1.4 \\
\hline $\begin{array}{l}\text { Employees choosing to stay or } \\
\text { remain in employment with } \\
\mathrm{KCM}\end{array}$ & 25.6 & 39.1 & 15.3 & 15.7 & 4.4 \\
\hline $\begin{array}{l}\text { Contributes to employee } \\
\text { morale and satisfaction }\end{array}$ & 22.3 & 46.9 & 16.8 & 11.0 & 2.9 \\
\hline $\begin{array}{l}\text { Health Services are easy } \\
\text { to reach, utilize; } \\
\text { there is no concern to } \\
\text { seek other health services }\end{array}$ & 16.8 & 38.8 & 15.0 & 23.8 & 5.5 \\
\hline $\begin{array}{l}\text { KCM medical services } \\
\text { are the most valued } \\
\text { employee benefits }\end{array}$ & 18.8 & 37.2 & 21.7 & 19.1 & 3.2 \\
\hline $\begin{array}{l}\text { KCM medical services } \\
\text { was an important factor } \\
\text { in selecting KCM } \\
\text { as an employer }\end{array}$ & 13.9 & 37.9 & 19.3 & 25 & 3.9 \\
\hline $\begin{array}{l}\text { KCM is better off financially } \\
\text { by not providing employee } \\
\text { medical services }\end{array}$ & 3.5 & 6.3 & 7.4 & 43.7 & 39.1 \\
\hline $\begin{array}{l}\text { KCM can perform better } \\
\text { in terms of operations } \\
\text { and production without } \\
\text { the medical services }\end{array}$ & 2.5 & 3.9 & 7.1 & 38.9 & 47.7 \\
\hline
\end{tabular}

As Table 1 describes, a large proportion of survey respondents considered the following as the most important attributes of KCM medical services, based on the order of the highest combined rating of agreement ("agree" and "strongly agree"):

- staying healthy $(90.6 \%)$,

- being productive $(88.4 \%)$,

- maintaining the health of family members $(88.4 \%)$, and

- assuring financial protection (85.9\%). 
Table 2. Importance of KCM Medical Services to KCM Organization

\begin{tabular}{|c|c|c|c|c|c|}
\hline Factor & & & Rating (\% & & \\
\hline & $\begin{array}{c}\text { Strongly } \\
\text { Agree }\end{array}$ & Agree & $\begin{array}{c}\text { Neither } \\
\text { Agree nor } \\
\text { Disagree }\end{array}$ & Disagree & $\begin{array}{l}\text { Strongly } \\
\text { Disagree }\end{array}$ \\
\hline $\begin{array}{l}\text { Financial protection to } \\
\text { employees }\end{array}$ & 78 & 22 & 0 & 0 & 0 \\
\hline $\begin{array}{l}\text { Success and performance of } \\
\text { the organization }\end{array}$ & 78 & 22 & 0 & 0 & 0 \\
\hline Employees staying healthy & 67 & 33 & 0 & 0 & 0 \\
\hline Productivity or performance & 67 & 33 & 0 & 0 & 0 \\
\hline Employee retention & 11 & 56 & 22 & 11 & 0 \\
\hline $\begin{array}{l}\text { Improving employee morale } \\
\text { and satisfaction }\end{array}$ & 0 & 75 & 25 & 0 & 0 \\
\hline $\begin{array}{l}\text { Reducing employee } \\
\text { absenteeism }\end{array}$ & 11 & 67 & 11 & 11 & 0 \\
\hline $\begin{array}{l}\text { Attracting new and } \\
\text { skilled/highly qualified } \\
\text { employees }\end{array}$ & 11 & 44 & 22 & 22 & 0 \\
\hline $\begin{array}{l}\text { More cost effective for the } \\
\text { organization to provide } \\
\text { medical services }\end{array}$ & 22 & 67 & 11 & 0 & 0 \\
\hline $\begin{array}{l}\text { Medical services are among } \\
\text { the most valued employee } \\
\text { services }\end{array}$ & 22 & 56 & 22 & 0 & 0 \\
\hline $\begin{array}{l}\text { Plays an important role in } \\
\text { KCM's corporate image and } \\
\text { social responsibility activities }\end{array}$ & 56 & 44 & 0 & 0 & 0 \\
\hline $\begin{array}{l}\text { KCM will be better off } \\
\text { financially by not providing } \\
\text { employee health services }\end{array}$ & 0 & 11 & 11 & 44 & 33 \\
\hline $\begin{array}{l}\text { KCM can perform better in } \\
\text { terms of operations \& } \\
\text { production without the medical } \\
\text { services }\end{array}$ & 0 & 0 & 0 & 44 & 56 \\
\hline
\end{tabular}

Other factors that survey respondents rated highly, were contributions of the medical services to employee morale and satisfaction (69.2\%) and selection of $\mathrm{KCM}$ as an employer based on KCM medical services (51.8\%). 
Figure 2. Importance of Medical Services to KCM as an Organization

1. Compliance with mining regulations: Healthcare services contribute to the Company's compliance with regulatory standards, e.g., First Aid, periodic health monitoring.

2. Source of revenue: By providing healthcare services to the community, to other companies, and to other mines, the Medical Services Department can generate revenue.

3. Reduces costs of employee medical expenses: Holistic/comprehensive medical services to employees and their dependents, along with preventive healthcare services to employees, dependants, and residents of communities in which KCM operates, all contribute to a lower disease burden, helping the Company substantially reduce ancillary health-related costs.

4. Company cares about its workforce: By providing healthcare services, the Company shows that it cares for its employees, demonstrating that they are an important, valued part of the Company.

5. Improves productivity: By working to keep employees healthy, the Medical Services Department fosters significantly better employee workplace attendance and helps sustain higher levels of employee productivity. Also, directly monitoring employee health allows the Company to deal with workplace safety concerns and outbreaks of disease more quickly and effectively.

6. Healthy workforce: Through regular medical check-ups and screening, the Medical Services Department can detect employees' chronic or developing medical conditions earlier, before they become more severe, creating tremendous cost savings for the Company.

7. First Aid, Occupational Health, and Public Health sections of the Medical Services Department: Crucial for the smooth running of mining operations, The Medical Services Department handles both urgent and routine medical issues, as well as providing an advisory role to the Company in setting policy and in revising operations to cope with larger medical issues.

8. Reliable access to medical services: The Medical Services Department provides employees readily available access to quick, reliable medical care, especially in emergencies and in mining injury cases, which often present immediate, specialized, and especially demanding medical issues. A well-run Department also reduces employees' concerns about long queues for emergency services, lengthy delays for routine medical services, and crowded wards.

9. Corporate Social Responsibility: The Medical Services Department enhance and promote corporate social responsibility activities, giving the Company a better public profile and better esteem among employees, regulators, and the public alike.

As confirmed in Table 2, areas in which all management respondents indicated agreement ("agree" or "strongly agree") that company-sponsored medical services were important included five specific benefits: provision of financial protection, organizational success and performance, employee health maintenance, employee productivity (all four at the top of the Table), and enhancement of KCM's corporate image and social responsibility (near the bottom of the Table). Management respondents also rated the following factors highly, based on the order of the highest combined rating of agreement ("agree" and "strongly agree"): more cost effectiveness by directly providing medical services $(89.0 \%)$, reduction of employee absenteeism (78.0\%), and being the most valued employee services (78.0\%). Management respondents gave similar responses to those of employees that, without medical services to employees, the KCM company would not perform better financially or logistically in operations and production. Management respondents highlighted the importance of the KCM company medical services to the KCM organization, as shown in Table 2. 
Table 3. Employee Satisfaction with Medical Services

\begin{tabular}{|l|c|c|c|c|c|}
\hline & \multicolumn{5}{|c|}{ Rating (N) } \\
\hline & Very Good & Good & Average & Poor & Very Poor \\
\hline KCM Grade & & & & & \\
\hline KCM1 & 3 & 1 & 2 & 2 & 0 \\
\hline KCM2 & 7 & 8 & 7 & 3 & 2 \\
\hline KCM3 & 6 & 17 & 23 & 6 & 4 \\
\hline KCM4 & 3 & 31 & 38 & 4 & 7 \\
\hline KCM5 & 14 & 27 & 47 & 3 & 5 \\
\hline KCM6 & 1 & 1 & 3 & 0 & 0 \\
\hline KCM7 & 0 & 1 & 0 & 0 & 0 \\
\hline KCM8 & 0 & 1 & 0 & 0 & 0 \\
\hline \% of Total & $11.9 \%$ & $31.2 \%$ & $43.9 \%$ & $6.7 \%$ & $6.3 \%$ \\
\hline Gender & & & & & \\
\hline Male & 27 & 61 & 88 & 17 & 15 \\
\hline Female & 7 & 28 & 37 & 2 & 3 \\
\hline IBU & & & & & \\
\hline Nchanga & 13 & 40 & 54 & 6 & 4 \\
\hline Konkola & 13 & 36 & 47 & 8 & 6 \\
\hline Nchanga Smelter & 2 & 7 & 8 & 2 & 3 \\
\hline Nkana & 1 & 3 & 12 & 2 & 2 \\
\hline Corporate & 5 & 3 & 4 & 1 & 4 \\
\hline Management Ratings & & $44.4 \%$ & $44.4 \%$ & $11.1 \%$ & \\
\hline $\begin{array}{l}\text { on employee satisfaction } \\
\text { with medical services }\end{array}$ & & & & & \\
\hline
\end{tabular}

Management respondents provided further insight as to why they believed medical services were important to the KCM organization, from legal, financial, and organizational perspectives, set forth in Figure 2.

By providing medical services to employees, KCM not only meets its legal and social responsibilities, but also gains multi-level financial benefits through increased productivity, reduced medical expenses, and additional generated revenues. Despite the obvious importance and value of employee health services, employee satisfaction levels with the services were disappointingly low. Only $44 \%$ of the employees surveyed rated the medical services delivered as "average," as noted in Table 3. This satisfaction level was notable across the various categories of employees, gender, and IBUs - except for corporate/management employees who were more inclined to rate their satisfaction as "good" or "very good." 
Table 4. Management Responses on Changes Required to Sustain the KCM Medical Services

\begin{tabular}{|c|c|c|c|c|}
\hline \multicolumn{5}{|c|}{ Changes that can Contribute to the Sustainability of the KCM Medical Services } \\
\hline $\begin{array}{l}\text { Address } \\
\text { Inefficiencies }\end{array}$ & $\begin{array}{c}\text { Employee } \\
\text { Contributions }\end{array}$ & $\begin{array}{c}\text { Healthcare } \\
\text { Human } \\
\text { Resource } \\
\text { Investment } \\
\end{array}$ & $\begin{array}{c}\text { Fresh } \\
\text { Re-investment }\end{array}$ & $\begin{array}{c}\text { Commercial- } \\
\text { ization }\end{array}$ \\
\hline $\begin{array}{l}\text { Procurement } \\
\text { processes } \\
\text { Eliminate wastage } \\
\text { and leakages of } \\
\text { resources in the } \\
\text { department }\end{array}$ & $\begin{array}{l}\text { Introduce a } \\
\text { policy for } \\
\text { employees to } \\
\text { contribute to } \\
\text { medical services }\end{array}$ & $\begin{array}{l}\text { Invest in the } \\
\text { training of } \\
\text { healthcare } \\
\text { workers (HCWs) } \\
\text { Address retention } \\
\text { of healthcare } \\
\text { workers }\end{array}$ & $\begin{array}{l}\text { Investment in } \\
\text { modern medical } \\
\text { equipment, } \\
\text { diagnostic } \\
\text { equipment and } \\
\text { infrastructure }\end{array}$ & $\begin{array}{l}\text { Financial and } \\
\text { commercial } \\
\text { autonomy } \\
\text { Re-branding } \\
\text { and enhanced } \\
\text { marketing of } \\
\text { the services }\end{array}$ \\
\hline Billing & & Recruitment of & & Partnerships \\
\hline $\begin{array}{l}\text { Reduce waiting } \\
\text { time }\end{array}$ & & $\begin{array}{l}\text { healthcare } \\
\text { workers }\end{array}$ & & $\begin{array}{l}\text { with other } \\
\text { organisations }\end{array}$ \\
\hline $\begin{array}{l}\text { Service delivery } \\
\text { Maintenance of } \\
\text { infrastructure }\end{array}$ & & $\begin{array}{l}\text { Address } \\
\text { motivation, } \\
\text { recognition and } \\
\text { conditions of } \\
\text { service of HCWs }\end{array}$ & & $\begin{array}{l}\text { Expansion of } \\
\text { the scope of } \\
\text { services }\end{array}$ \\
\hline
\end{tabular}

As displayed in Table 4, investing in healthcare workers in the medical department at KCM is critical - both to improve the service quality and to enhance the sustainability of KCM's medical services program. Management respondents offered diverse suggestions on what changes would enable the Medical Services Department to become more self-sustainable, including addressing the Medical Services Department's inefficiencies, introducing employee financial contributions, investing in human resources, financing new medical equipment, and commercializing the Department's operations, especially by forming new partnerships. As a global funding suggestion, management respondents submitted that KCM finance its medical services program based on a recommended per capita healthcare funding standard, encompassing employees, dependents, retired employees with their dependents, and former miners entitled to medical services for life due to work-related injuries.

\section{Discussion}

This study confirmed that medical services are vitally important both to KCM as an organization and to its employees. Significant factors revealed during the study - such as, employee financial protection, employee health and productivity, employee retention, and employee morale - are the same factors identified in literature (Willmer et al. 2018, Troy 2016, Conference Board of Canada 2014). These same factors also are noted as contributing to the organization's overall success. As also revealed in our study, financial protection is a key benefit of 
employee health services, serving to reduce the risk of runaway expense from a catastrophic health event or condition, known to lead to impoverishment among employees (Koyi 2019). By minimizing employee concerns in seeking healthcare services for their families and for themselves, an organization again can realize employee productivity increases by allowing employees to focus on their work another substantial collateral benefit for the organization (Ammendolia et al. 2016, Meyer-Rath et al. 2015, Chuma et al. 2013). Further, organizations have come to realize that by failing to invest in employee healthcare, they become liable to bear many indirect, less obvious costs arising from poor employee health (Troy 2016, Eyestone et al. 2014, Porter et al. 2008). Our study's parallel results corroborated that, despite the upfront expenditures involved, investment in employee healthcare is more cost-effective overall for organizations generally and particularly for organizations, such as KCM, in high-hazard industries.

It is interesting to note that, despite the employee health services being vitally important, employee satisfaction levels with those in-house services rated only average, at best. This lack of satisfaction may have several root causes, but two reparable ones are obvious. First, the employee dissatisfaction may reflect that the delivery of medical services is below employee expectations, particularly in comparison to the delivery by private providers. Second, employee dissatisfaction may reflect inefficiencies in delivery of the medical services, caused at least in part by budgetary constraints/inadequate funding.

Accordingly, because mining company budgets are increasingly stretched, in order to improve employee satisfaction with medical services KCM needs to focus on value in healthcare service delivery. $\mathrm{KCM}$ needs make greater efforts to raise employee satisfaction levels by having healthcare professionals thoroughly examine the existing healthcare structure to locate and remove inefficiencies, thus increasing the quality of the services provided while maintaining the department's existing resources. KCM should consider better scheduling for the medical service department, to make service delivery more convenient for employees. KCM also should consider a reallocation of funds, to direct more monies to those healthcare needs/services that employees need and value most.

Regardless of the specific methodology for improvement, better health outcomes and improved efficiency generally are key components in lowering healthcare costs. Rather than simply slashing the budget or adopting harsh and impracticable cost-reduction initiatives, obtaining better value from the existing expenditures likely will be more successful (Conference Board of Canada 2014, WHO 2010). Addressing organizational effectiveness and inefficiencies in healthcare delivery not only contributes to lowering healthcare costs, but also improves the service delivery and performance. Inefficiencies in procurement practices and underutilization of information technology specifically were noted to be major inefficiencies in KCM's Medical Services Department.

In addition, purposeful expansion of the certain aspects of healthcare service delivery may come even with company cost-cutting, by broadening funding sources beyond company resources. Attracting commercial healthcare sponsorship and/or pharmaceutical co-branding could expand the company's healthcare budget; reduce costs to the company, employees, and their families; co-sponsor 
and/or introduce new and existing needed services; and increase program goodwill, raising employee satisfaction levels overall.

In terms of managing its most important asset - the workforce - an organization benefits from providing healthcare services to employees, including through the retention of able, trained, healthy employees, as our study reveals. Both from a financial and an operational perspective, organizations perform better by investing in employee health services. But, sustaining those medical services requires addressing inefficiencies, re-investing in healthcare equipment and workers, and obtaining employee buy-ins, including through financial contributions.

Earmarking employee contributions is an innovative way of sourcing healthcare financing. For an organization such as KCM to undertake this model of healthcare financing, there needs considerable trust among employer, union leaders, and employees alike, so that funds, once collected, are properly utilized for their intended healthcare services purpose. Skillful bargaining, proper documentation, and thorough program oversight are necessary to secure cooperation from unions, a critical component in successfully implementing and maintaining mandatory employee contributions to help fund company healthcare. Unions have a powerful, influential role when it comes to addressing employee health benefits (Thornton 2017, Chuma et al. 2013, WHO 2013). In fact, as management respondents recognized, without union endorsement and validation, substantial novel employee policies either will fail to be implemented or will wither a short time after implementation. Accordingly, this distinctive form of financing for company healthcare services requires an on-going, trust-based company engagement with employee unions and their leadership.

\section{Conclusion}

Organizations such as $\mathrm{KCM}$ are making an important investment in their employees and businesses by providing company-sponsored healthcare services. Findings from numerous observations and studies, including ours, shed light on the close associations between organizational and financial investment in employee healthcare services and employee satisfaction. Moreover, consistent data supports the benefits of multi-level strategies for promoting the worker health, particularly in demanding industries such as mining (Martin et. al 2016). It is recommended that organizations should promote employee health through a culture of health and complementary activities, including wellness programs, disease management programs, and screening and prevention programs for chronic diseases. Implementing these activities and human behavior-based strategies helps establish and encourage a culture of health among workers, empowering employees to be more cognizant of and engaged in their health and lifestyle decisions. In turn, this implementation offers employers direct and indirect benefits, such as healthier employees with fewer health complications, reduced numbers of employee hospital admissions, and lower future healthcare costs overall (Son and SouthWinter 2018, Haas et al. 2016). 
In addition to providing the aforementioned programs and activities, it is recommended that mining companies form partnerships with healthcare authorities in Africa, to provide adequate treatment programs for diseases prevalent in mining workers (e.g., tuberculosis). Further, mining companies in Africa should comply fully with occupational health and safety standards. Unfortunately, enforcing mining company compliance with these standards has remained a critical challenge (Osewe 2015).

Many Sub-Saharan African countries are increasingly seeking to impose lower out-of-pocket payments for workers, while striving towards domestic mandatory pre-payment financing within contributory health insurance schemes (McIntyre et al. 2018). The WHO (2010) recommends that organizations should be encouraged to utilize pre-payment models, because they are more efficient and equitable. Various models have been developed in which a proportion of contributions towards life insurance and retirement plans are put aside as savings, accruing interest over time and generating a fund that can finance both an employee's current healthcare needs and that employee's retirement healthcare costs (National Insurance Services of Wisconsin 2012). KCM may explore and analyze these models to develop a stable system of healthcare financing for its retirees and ex-miners, who currently have a five-year access to free healthcare (Muchemwa and Karim 2017). Our research suggests implementing pre-payment employee medical plans is a viable funding option.

Our study was limited to a single mining company in Zambia, which seems to provide thorough, but largely anecdotal data. It is recommended that this same study be conducted in several mines within the region to ascertain whether our findings will be verified further and yield even more compelling evidence supporting our recommendations. Furthermore, it would also be worthwhile to investigate the reasons that mine workers most often resist making financial contributions towards their healthcare services.

Bearing these limitations in mind, the results of our study bring a basic understanding of the multi-level strategies most beneficial for promoting the health of mining industry workers in Zambia. Clearly, more needs to be done to raise the levels of employee satisfaction with the healthcare services actually being delivered. Organizations, such as KCM, that have made similar surveys should consider follow-up studies of both employee satisfaction and management satisfaction with the company healthcare programs and with the healthcare services being delivered by those programs. These studies can work not merely as a ratings system, but, far more importantly, to provide data for a realistic evaluation of the efficacy of the system, of the appropriateness of its overall funding levels, and of the proper distribution of those funds within the system. With these studies at regular intervals, an organization can more thoroughly evaluate the system to determine its effectiveness, can consider whether alternatives would be more efficacious, and can adapt the system to meet the changing needs of the workforce.

Despite privatization of the Zambian mining industry over 20 years ago, there remains relatively limited information on its employee healthcare services, further suggesting that additional, in-depth studies are necessary. These additional studies would be greatly instructive, particularly considering the broad, valuable insights 
gained from our seemingly anecdotal data. The context of other studies, both of the mining industry and other industries, should provide many common principles and recommendations - principles and recommendations that can apply not only to the Zambian mining industry, not only to the mining industry as a whole, not only to other high-hazard industries, but also to industry globally.

\section{Acknowledgments}

The advice of the anonymous referees is gratefully acknowledged as important in helping in the completion of the final revision of this paper.

\section{References}

Ammendolia C, Côté P, Cancelliere C, Cassidy JD, Hartvigsen J, Boyle E et al. (2016) Healthy and productive workers: using intervention mapping to design a workplace health promotion and wellness program to improve presenteeism. BMC Public Health 16(1): 1190.

Bakker AB, Demerouti E (2018) Multiple levels in job demands-resources theory: implications for employee well-being and performance. In E Diener, S Oishi, L Tay (eds.), Handbook of Wellbeing. Salt Lake City, UT: DEF Publishers.

Bloch K, Johnson LF, Nkosi M, Ehrlich R (2018) Precarious transition: a mortality study of south African ex-miners. BMC Public Health 18(1): 862.

Blumberg LJ, Buettengens M, Feder J, Holahan J (2012) Why employers will continue to provide health insurance: the impact of the affordable care act. Inquiry 49(2): 116126.

Chuma J, Mulupi S, McIntyre D (2013) Providing financial protection and funding health service benefits for the informal sector: evidence from Sub-Saharan Africa. Working Paper 2. Cape Town: RESYST.

Conference Board of Canada (2014) Challenging health care system sustainability understanding health system performance of leading countries. Ottawa.

Di Fabio A (2017) Positive healthy organizations: promoting well-being, meaningfulness, and sustainability in organizations. Frontiers in Psychology 8(Nov): 1-6.

Dixon-Fyle S, Gandhi S, Pellathy T, Spatharou A (2012) Changing patient behavior: the next frontier in healthcare value. Health International 12(Sep): 64-73.

Eyestone M, Moore KD, Coddington DC (2014) Understanding self-funding. Healthcare Financial Management 68(2): 112-114.

Golden S, Earp J (2012) Social ecological approaches to individuals and their contexts: twenty years of health education and behavior health promotion interventions. Health Education \& Behavior 39(3): 364-372.

Gould E (2013) Increased health care cost sharing works as intended: it burdens patients who need care the most. Briefing Paper \#358. Economic Policy Institute.

Grawitch MJ, Ballard DW (2016) The psychologically healthy workplace: building a winwin environment for organizations and employees. Washington, DC: American Psychological Association.

Gray P, Senabe S, Naicker N, Kgalamono S, Yassi A, Spiegel J (2019) Workplace-based organizational interventions promoting mental health and happiness among healthcare 
workers: a realist review. International Journal of Environmental Research and Public Health 16(22): 4396.

Haas EJ, Cecala AB, Hoebbel CL (2016) Using dust assessment technology to leverage mine site manager-worker communication and health behavior: a longitudinal case study. Journal of Progressive Research in Social Sciences 3(1): 154-167.

Hairong Y, Sautman B (2013) The beginning of a world empire? Contesting the discourse of Chinese copper mining in Zambia. Modern China 39(2): 131-164.

Hendriksen IJ, Snoijer M, de Kok BP, van Vilsteren J, Hofstetter H (2016) Effectiveness of a multilevel workplace health promotion program on vitality, health, and workrelated outcomes. Journal of Occupational and Environmental Medicine 58(6): 575583.

HRET - Kaiser Family Foundation and Health Research \& Educational Trust (2015) Employer Health Benefits 2015 Summary Findings. Kaiser Family Foundation.

Kaol G, Wambalaba F (2011) Homegrown Kenya: the horticultural industry under fire on CSR. Emerald Emerging Markets Case Studies 1(1): 1-14.

Koyi G (2019) Working and living conditions of workers in the mining sector in Zambia. ALREI.org.

Martin A, Karanika-Murray M, Biron C, Sanderson K (2016) The psychosocial work environment, employee mental health and organizational interventions: improving research and practice by taking a multilevel approach. Stress and Health 32(3): 201215.

McIntyre D, Amarech G, Obse E, Barasa W, Ataguba JE (2018) Challenges in financing universal health coverage in sub-Saharan Africa. Health Economics Online Publication. DOI=10.1093/acrefore/9780190625979.013.28.

Meyer-Rath G, Pienaar J, Brink B, van Zyl A, Muirhead D, Grant A et al. (2015) The impact of company-level ART provision to a mining workforce in South Africa: a cost-benefit analysis. PLoS Medicine 12(9): e1001869.

Michaels CN, Greene AM (2013) Worksite wellness: increasing adoption of workplace health promotion programs. Health Promotion Practice 14(4): 473-479.

Ministry of Health Zambia and EQUINET (2018) Mining and public health in Zambia: meeting report. Lusaka, Zambia.

Muchemwa V, Karim AW (2017) Critical literature review on safety and health hazards as operational risks affecting mining. International Journal of Multidisciplinary Research and Development 4(9): 125-134.

Murphy F (2015) Community trust: a moral issue for health care providers. Springer.

National Insurance Services of Wisconsin (2012) Understanding self-funded vs. fully insured health plans. Retrieved from: https:/www.nisbenefits.com/wp-content/uplo ads/2015/11/NIS-Self-Funding.pdf. [Accessed 31 May 2020]

Nkombo G, Abubakar B (2002) To privatise or not? The case of Zambia. Africa Insight 32(4): 12-20.

Nyström ME, Höög E, Garvare R, Andersson Bäck M, Terris D, Hansson J (2018) Exploring the potential of a multi-level approach to improve capability for continuous organizational improvement and learning in a Swedish healthcare region. BMC Health Services Research 18(1): 376.

Osewe P (2015) Better health in mines and mining communities: a shared responsibility world bank blog. Retrieved from: https://blogs.worldbank.org/health/better-healthmines-and-mining-communities-shared-responsibility. [Accessed 20 May 2020]

Parker AW, Tons MJ, Ritchie GE (2017) Development of a multilevel health and safety climate survey tool within a mining setting. Journal of Safety Research 62(Sep): 173-180. 
Porter M, Teisberg E, Wallace S (2008) What should employers do about healthcare. Harvard Business School.

Prowle MJ, Harradine D (2015) Sustainable health services: an international study. Technical Report. London: Association of Chartered Certified Accountants.

Reddick C, Coggburn J (2007) State government employee benefits in the United States Choices and effectiveness. Review of Public Personnel Administration 22(1): 5-20.

Sadia R (2016) The relationship between employee health, quality, culture, and organizational effectiveness: findings from the literature. International Journal of Design \& Nature and Ecodynamics 11(1): 1-9.

Self-Insurance Institute of America (2009) Understanding self-insured group health plans: solutions for containing costs while providing quality benefits. Self-Insurance Institute of America.

Son BW, South-Winter C (2018) Human behavior impacts on health care. Journal of International \& Interdisciplinary Business Research 5(8): 138-146.

Stewart P, Bezuidenhout A, Bischoff C (2019) Safety and health before and after Marikana: subcontracting, illegal mining, and trade union rivalry in the South African mining industry. Review of African Political Economy 47(163): 27-44.

Thornton N (May) Miners get permanent funding for health care, but fate of pensions is dubious. BenefitsPro Magazine.

Tong R, Zhang Y, Yang Y, Jia Q, Ma X, Shao G (2019) Evaluating targeted intervention on coal miners' unsafe behavior. International Journal of Environmental Research and Public Health 16(3): 422.

Troy T (2016) A Better Way for Employer Sponsored Healthcare. Forbes.

Walters D, Quinlan M (2019) Voice and resistance: coalminers' struggles to represent their health and safety interests in Australia and New Zealand 1871-1925. The Economic and Labour Relations Review 30(4): 513-531.

Willmer D, Haas E, Steiner L (2018) Human factors considerations in addressing mining occupational illnesses, injuries, and fatalities. The National Institute for Occupational Safety and Health.

World Factbook (2020) Africa: Zambia. Central Intelligence Agency.

WHO - World Health Organization (2010) The role of innovative financing mechanisms for health. Background Paper 12.

WHO - World Health Organization (2018) Noncommunicable diseases (NCD) country profiles.

WHO - World Health Organization -Regional Office for Africa (2013) State of world health financing in the African Region. 
